\title{
Effect modification of the association between meteorological variables and mortality by urban climatic conditions in the tropical city of Kaohsiung, Taiwan
}

\author{
William B. Goggins ${ }^{1}$, Chao Ren ${ }^{2}$, Edward Ng${ }^{2}$, Chunyuh Yang 3 , Emily Y.Y. Chan ${ }^{4}$
}

\begin{abstract}
${ }^{1}$ Division of Biostatistics, School of Public Health and Primary Care, The Chinese University of Hong Kong, Shatin, Hong Kong, People's Republic of China; ${ }^{2}$ Department of Architecture, The Chinese University of Hong Kong, Shatin, Hong Kong, People's Republic of China; ${ }^{3}$ Institute of Public Health, Kaohsiung Medical University, Kaohsiung, Taiwan; ${ }^{4}$ Division of Family Medicine, School of Public Health and Primary Care, Chinese University of Hong Kong, Hong Kong, People's Republic of China
\end{abstract}

\begin{abstract}
A deeper understanding of extreme hot weather are needed in cities sensitive to heat effects, an investigation was done in the tropical town of Kaohsiung in Taiwan. Its 11 districts were divided into three climatic classes varying from high urban heat, low levels of green space and lack of proximity to water bodies to low urban heat, adequate green space and proximity to water bodies. Daily data on natural mortality, meteorological variables, and pollutants from May-October 1999-2008 were analysed using generalised additive models for the time-series data. Subgroup analyses were conducted, stratifying decedents according to the level of planning activity required in order to mitigate adverse heat effects in their residential areas, classifying districts as "level 1" for those requiring a high level of mitigation action; "level 2" for those requiring some action; and "level 3" for those that need only preserve existing conditions. Stratified analyses showed that mortality increases per $1{ }^{\circ} \mathrm{C}$ rise on average, either on the same day or in the previous 4 days (lags $0-4$ ), were associated with $2.8 \%, 2.3 \%$ and $-1.3 \%$ for level 1,2 and 3 districts, respectively. The slope describing the association between temperature and mortality was higher above $29.0{ }^{\circ} \mathrm{C}$ resulting in corresponding increases of $4.2 \%, 5.0 \%$ and $0.3 \%$ per per $1{ }^{\circ} \mathrm{C}$ rise in temperature, respectively. Other meteorological variables were not significantly associated with mortality. It is concluded that hot season mortality in Kaohsiung is only sensitive to heat effects in districts classified as having unfavourably climatic conditions and requiring mitigation efforts in city planning. Urban planning measures designed to improve climatic conditions could reduce excess mortality resulting from extreme hot weather.
\end{abstract}

Keywords: Green spaces, extreme weather events, global warming, environmental epidemiology, time-series models, population health, Taiwan.

\section{Introduction}

The reality of climate change has focused attention on the potential of adverse health consequences resulting from extreme, high temperatures. While strategies to mitigate future climate change through reduction of greenhouse gas emissions remain critical, adaptation is essential as climate change is now seen as unavoidable due to the anticipated time lag between implementation of measures to reduce greenhouse gas emissions and their effects on the world climate (Pielke et al., 2007). In 2008, the World Health

Corresponding author:

William B. Goggins

Division of Biostatistics, School of Public Health and Primary Care

The Chinese University of Hong Kong, Shatin, Hong Kong

Tel. +852 2632 2918; Fax +852 26321792

E-mail: wgoggins@cuhk.edu.hk
Organization (WHO) passed a resolution which includes the health impacts of mitigation and adaptation policies as one of five key areas for research in the area of climate change and human health (Hosking and Campbell-Lendrum, 2012). One way that cities can adapt to the hotter temperatures resulting from climate change is to lessen the impact of the urban heat island (UHI) effect through better urban design (Luber and McGeehin, 2008). Knowledge of which areas of a city are particularly vulnerable to UHI effects would aid city planners in knowing where to focus their efforts. The urban climatic map (UCMap) concept uses available, meteorological data, geographical information and planning information on several parameters important for the urban climate to identify areas of a city that may be particularly sensitive to UHI effects (Ren et al., 2011). This concept can be used for planning recommendations from the climatic point of view. 
The expected increase in mortality due to the higher frequency of extreme, hot weather is a prominent outcome of climate change. Numerous studies have examined the short-term association between daily ambient temperatures and mortality, and most of them have found increases during periods of both very hot and very cold weather (Braga et al., 2002; Curriero et al., 2002; Carder et al., 2005; Ishigami et al., 2008; McMichael et al., 2008; Chan et al., 2012). Studies looking at the potential modification of the effect of hot weather on mortality due to urban features, such as that of the UHI effect, are less common. Our previous Hong Kong-based study (Goggins et al., 2012) classified geographic areas of that city according to an UHI index (UHII) and found that higher mortality was significantly associated with mean temperatures above $29^{\circ} \mathrm{C}$ and low mean wind speeds in areas with the UHII above the median value, while it had no association with these parameters in areas with the UHII below the median.

Kaohsiung, a port city in south-eastern Taiwan and the second largest city in the country, had a population of 1.53 million at the end of 2010 (Kaohsiung City Government, 2011). Its climate is tropical with a hot season between May and October, during which period the mean monthly temperatures exceed $27^{\circ} \mathrm{C}$. The population density for the city as a whole is $9,961 \mathrm{per}$ $\mathrm{km}^{2}$, but in the districts in central Kaohsiung the density ranges from about 15,000 per $\mathrm{km}^{2}$ to 28,000 per $\mathrm{km}^{2}$. The proportion of the population over 65 and 75 years of age is $10 \%$ and $4 \%$, respectively (Kaohsiung City Government, 2011).

In the current study, we examined whether areas of Kaohsiung, classified by the UCMap method as having unfavourable, urban, climatic characteristics prone to exposing residents to hot weather stress, indeed show greater increases in mortality during hot weather periods than areas with more favourable characteristics. These observations are important for decision-makers.

\section{Materials and methods}

\section{Data}

Daily deaths in Kaohsiung City for the period from 1 January 1999 to 31 December 2008 were obtained from the Taiwanese Department of Health, which is in charge of the national death registration system. For each death, detailed demographic information, including gender, date of death, date of birth, cause of death, place of death and residential district are recorded. Data on daily mean temperature, mean relative humid- ity $(\mathrm{RH})$, mean wind speed and total global solar radiation were provided by the Central Weather Bureau from a station located on the coastline of Kaohsiung harbour. The city has six air quality monitoring stations that are established and run by the Taiwanese Environmental Protection Administration (EPA). The monitoring stations are fully automated and provide daily readings ( 24 hour average of the measurements) on sulphur dioxide $\left(\mathrm{SO}_{2}\right)$ by ultraviolet fluorescence (Tsai et al., 2009), on particulate matter $<10 \mu \mathrm{m}$ $\left(\mathrm{PM}_{10}\right)$ by beta-ray absorption (Tsai et al., 2009), on nitrogen dioxide $\left(\mathrm{NO}_{2}\right)$ by ultraviolet fluorescence (Tsai et al., 2009), on carbon monoxide (CO) by nondispersive infrared photometry (Tsai et al., 2009) and on ozone $\left(\mathrm{O}_{3}\right)$ by ultraviolet photometry (Tsai et al., 2009). For each day, air pollution data were extracted from all monitoring stations and averaged. When data were missing for a particular monitoring station on a given day, the values from the remaining monitors were used to compute the average values.

\section{Urban climatic mapping}

The UCMap concept, first developed in the 1970s by researchers in Germany (Ren et al., 2011), collates information on meteorological conditions, land use, urban planning, topographic characteristics and vegetation to produce a two-dimensional map showing the variation in climatic conditions across cities (Ren et al., 2011). Various clima topes, i.e. areas showing similar urban climate characteristics, can be identified from this map (Ren et al., 2011). The UCMap for Kaohsiung was developed using a raster grid with $500 \times 500 \mathrm{~m}$ cells. The raster information included topography, population density, land use, UHII, natural landscape, water bodies, prevailing wind and the effects of land and sea breezes (Ren et al., 2013). The first four of these data classes influence the thermal environment and were therefore categorised as "thermal loads", while the green space, e.g. urban parks, forests and agricultural lands as well as water body systems including seas, rivers and ponds can be said to contribute to the "dynamic potential" as they provide ventilation and cooling for the surrounding areas (Ren et al., 2013). Information on prevailing winds including land and sea breezes, classified as "wind information", is important for urban planning. The Kaohsiung UCMap was created based on the information provided by these eight layers and includes also three levels of planning actions at the district level (Ren et al., 2013).

The UCMap approach was used to divide Kaohsiung's 11 districts into three climatic classes. 
The "level 1 class" consisted of three districts in the centre characterised by a very high thermal load together with a low dynamic potential and thus in need of a high level of mitigation activities including increasing greenery coverage and lowering anthropogenic heat release (Ren et al., 2013). Four districts with medium levels of UHII and a higher dynamic potential due to more green space were categorised as "level 2 districts" and judged to require some mitigation action, while "level 3" was reserved for four districts situated near water bodies and thus characterised by a low thermal load and high dynamic potential. This class was judged not to require any improvement other than preservation of existing conditions. Fig. 1 shows the map of Kaohsiung's districts with the three different levels of potential heat stress marked.

\section{Statistical analysis}

Analyses were restricted to the May-October period, i.e. the hot season. Poisson generalised additive models (GAM), described by Wood (2006), were used to model the association between the daily, non-accidental mortality and meteorological variables, while adjusting for pollutants, time trend (day of study $=1$, $\ldots ., 3653)$, seasonality (day of the year $=121, \ldots, 305)$ and day of the week. As a first step, distributed lag models (Armstrong, 2006) were fitted to the data to ascertain the lag effects of the meteorological variables. Maximum lags of 21 days for meteorological variables and 10 days for pollutants were initially allowed. After inspection of the results of the distributed lag models, it was decided to use the mean of lags 0-4 for both the meteorological and pollutant variables; thus subsequent models were fitted with smooth terms with 4 degrees of freedom each for the meteorological and pollutant variables. Pollutant variables were tried one at a time and in multi-pollutant models. None of the pollutant variables were statistically significant and the only one close to significance was ozone so only this variable was included in the final modelling. Models were fitted for all natural deaths and deaths were stratified into three groups by district level as described above. The models were also fitted for deaths stratified by gender and by age group $(<65,65-74$, and $>75$ years). To check for possible "harvesting", the shortterm bringing forward in time deaths that would have occurred within a few days, even without the environmental stressors, we also fitted models using the mean of lags 0-21 for each meteorological variable.

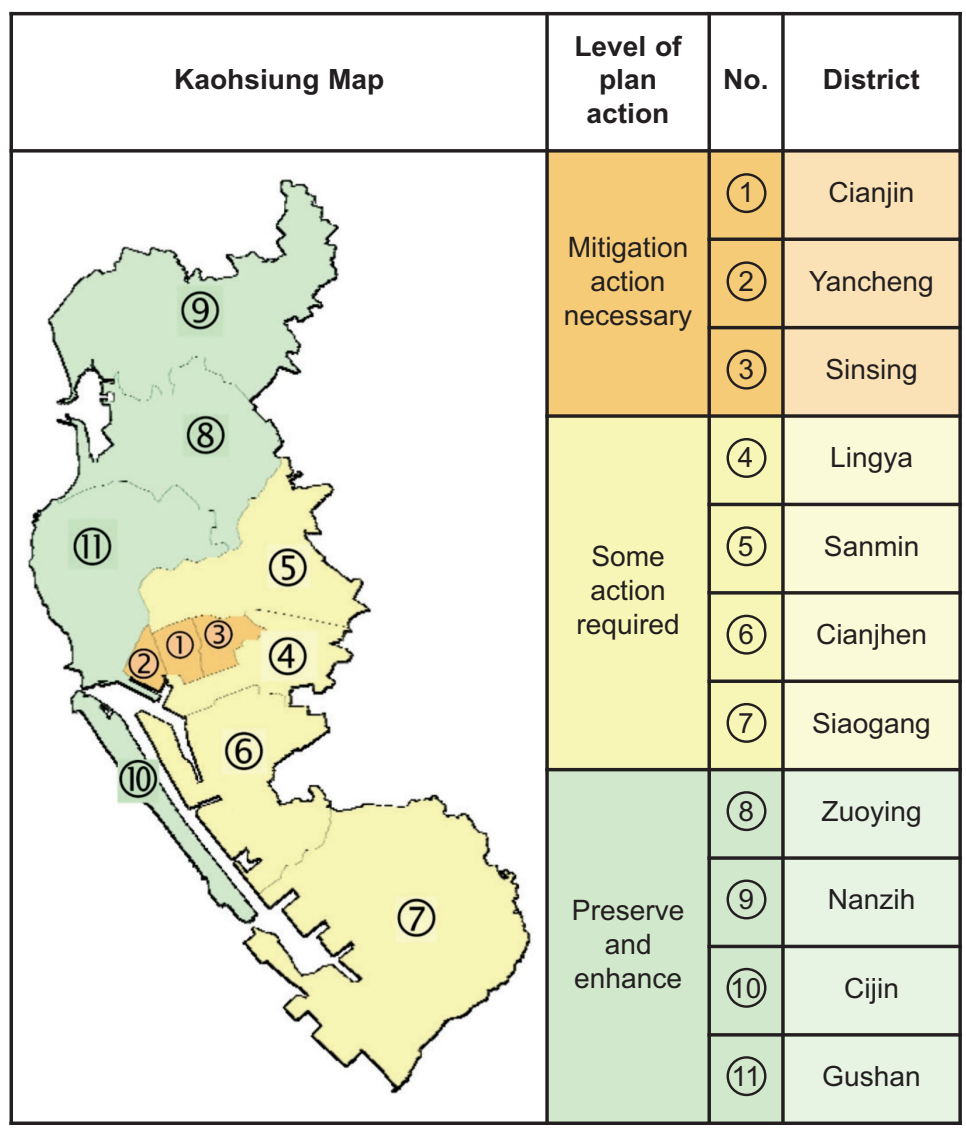

Fig. 1. Map of Kaohsiung districts showing the three levels of potential heat stress. 


\section{Results}

Descriptive statistics on the study variables are shown in Table 1 . About $11 \%$ of deaths occurred in level 1 districts, while about 56\% and 33\% occurred in the levels 2 and 3 districts, respectively.

Models for all natural deaths with smooth terms for average lag 0-4 mean temperature, $\mathrm{RH}$, wind speed, solar radiation and ozone, showed only a significant effect for temperature and this effect was positive over the range observed in the hot season with a higher slope for temperatures $>29.0{ }^{\circ} \mathrm{C}$ (Fig. 2). Higher humidity and ozone had weak and non-significant linear associations with higher mortality, while higher solar radiation and wind speed had weak, non-significant linear association with lower mortality. Since there were some missing data for solar radiation, this variable was excluded from subsequent models after confirmation that it did not play a substantial role, neither as predictor nor as confounder. Since all environmental variables showed a consistent association with mortality, we first fitted a model with linear terms for all the meteorological parameters and ozone. The results of this model are summarised in Table 2. From this model each $1{ }^{\circ} \mathrm{C}$ rise in mean temperature was significantly associated $(\mathrm{P}=0.014)$ with a $1.4 \%$ $(95 \%$ confidence interval $(\mathrm{CI})=0.3-2.5 \%)$ rise in natural mortality. In analyses stratified by category of district, $1{ }^{\circ} \mathrm{C}$ rises in the mean temperature were associated with $2.8 \%(\mathrm{P}=0.119)$ and $2.3 \%(\mathrm{P}=0.002)$ rises in mortality in levels 1 and 2 districts, respectively, while a $1{ }^{\circ} \mathrm{C}$ rise was associated with a non-significant $(\mathrm{P}=0.300) 1.2 \%$ drop in mortality for Level 3 districts. An analysis combining deaths in levels 1 and 2 districts into a single category was also performed due to the small sample size in the level 1 analysis and this showed a $2.3 \%$ rise $(P<0.001)$ for the combined category. The difference between the temperature parameters between the level $1+$ level 2 model and the level 3 model was statistically significant $(P=0.009)$. There was also a trend for the association between higher RH percent and higher ozone levels to be stronger in hotter areas, but none of the effects or differences between areas were statistically significant. Conversely, the association between lower wind speed and mortality was stronger in level 3 areas, but again this association was not significant in any of the subgroup analyses.

Since the slope describing the association between temperature and mortality was higher above $29.0{ }^{\circ} \mathrm{C}$ (Fig. 2) we also fitted models with temperature modelled using two piece-wise linear terms: $\mathrm{T}_{\mathrm{HOT}}=\mathrm{TEMP}_{0-4}$ 29.0, where $\mathrm{TEMP}_{0-4} \geq 29.0^{\circ} \mathrm{C}$ and otherwise $=0$ and $\mathrm{T}_{\text {WARM }}=29.0-\mathrm{TEMP}_{0-4}$, where $\mathrm{TEMP}_{0-4}<29.0^{\circ} \mathrm{C}$ and otherwise $=0$, where $\mathrm{TEMP}_{0-4}$ is the mean of lags $0-4$ mean daily temperatures.

Results of these models are shown in Table 3. For the model for all natural deaths, each $1{ }^{\circ} \mathrm{C}$ rise in mean temperature above $29.0{ }^{\circ} \mathrm{C}$ was significantly associated with a $3.4 \%$ rise $(P=0.017)$ in natural mortality. In analyses stratified by category of district, $1{ }^{\circ} \mathrm{C}$ rises in mean temperature above $29.0{ }^{\circ} \mathrm{C}$ were associated with $4.2 \%(\mathrm{P}=0.360)$ and $5.0 \%$ $(\mathrm{P}=0.010)$ rises in mortality in levels 1 and 2 districts, respectively, while a $1{ }^{\circ} \mathrm{C}$ rise was associated with a non-significant $0.3 \%(\mathrm{P}=0.899)$ rise in mortality for level 3 districts. The analysis combining deaths in levels 1 and 2 districts into a single category showed a $4.6 \%(\mathrm{P}=0.009)$ rise in mortality per $1{ }^{\circ} \mathrm{C}$ rises in mean temperature. There was also a trend for the

Table 1. Descriptive statistics for the study variables from May to October, 1999-2008.

\begin{tabular}{lrrrr}
\hline Variable & Mean $\left(\mathrm{SD}^{\mathrm{a}}\right)$ & Median $\left(\mathrm{IQR}^{\mathrm{b}}\right)$ & $5^{\text {th }}$-95 $5^{\text {th }}$ \%ile & Minimun-Maximun \\
\hline Mean daily temperature $\left({ }^{\circ} \mathrm{C}\right)$ & $28.4(1.5)$ & $28.6(27.5-29.5)$ & $25.6-30.6$ & $22.4-32.2$ \\
Mean relative humidity $(\%)$ & $76.3(7.1)$ & $76.0(71.6-80.0)$ & $65.4-89.0$ & $56.4-99.0$ \\
Mean wind speed $(\mathrm{m} / \mathrm{s})$ & $2.2(0.8)$ & $2.1(1.8-2.4)$ & $1.4-4.1$ & $0.9-13.1$ \\
Mean daily ozone $(\mathrm{ppb})$ & $27.7(14.4)$ & $25.4(15.3-38.5)$ & $9.7-53.3$ & $3.6-72.9$ \\
Daily natural deaths $(\mathrm{no})$. & $17.5(4.7)$ & $17(14-20)$ & $10-26$ & $3-33$ \\
Level 1 districts (hot) & $1.9(1.4)$ & $2(1-3)$ & $0-4$ & $0-7$ \\
Level 2 districts (warm) & $9.8(3.3)$ & $10(7-12)$ & $5-16$ & $0-25$ \\
Level 3 districts (cool) & $5.8(2.6)$ & $6(4-8)$ & $2-11$ & $0-15$ \\
Age $<$ 65 years & 5.1 & $5(3-7)$ & $2-9$ & $0-15$ \\
Age 65-74 years & 4.7 & $8(3-6)$ & $3-14$ & $0-14$ \\
Age $\geq 75$ years & 8.3 & & & $0-23$
\end{tabular}

a Standard deviation; ${ }^{\text {'} I Q R ~}=$ interquartile range $\left(25^{\text {th }}\right.$ percentile $-75^{\text {th }}$ percentile $)$. 


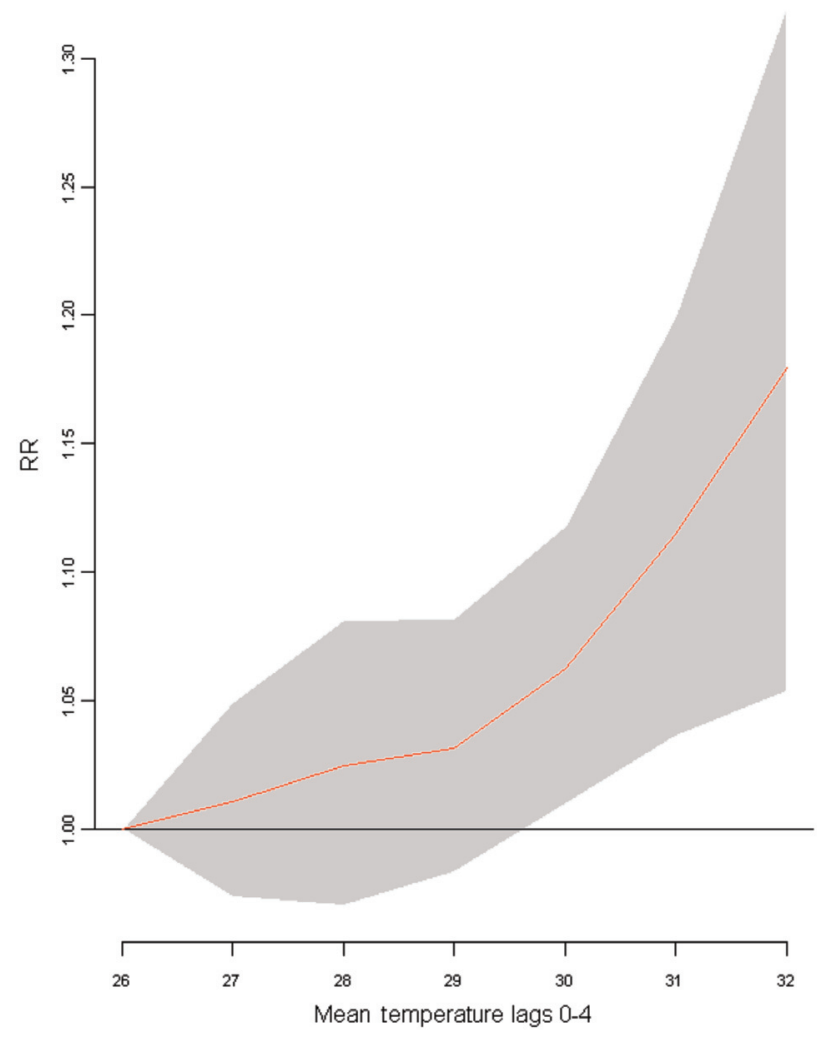

Fig. 2. Mortality from natural causes versus average lags 0-4 mean daily temperature, Kaohsiung Taiwan, May-October, 1999-2008. association between higher temperatures below $29.0{ }^{\circ} \mathrm{C}$ to be stronger for hotter areas but none of these results were statistically significant. The results for the other environmental parameters were very similar to those in Table 2 (not shown). In subgroup analyses by age there was a trend for older age groups to show a stronger effect for the linear temperature term (Table 2), with no association between higher temperature and mortality for the youngest age group considered ( $<65$ years old at death). However for the analysis using piecewise terms all three age groups showed similar associations for temperatures $>29^{\circ} \mathrm{C}$, with a trend only evident for temperatures $<29^{\circ} \mathrm{C}$. In subgroup analysis by gender estimates from both the linear and piecewise models were very similar for males and females (results not shown).

To test for the possible influence of short-term mortality displacement "harvesting", we also tried models with the averages of longer lags, lags $0-21$, for the meteorological variables. The results for these models gave estimates for linear temperature effects very close to those for the mean of lags $0-4$, increases per $1{ }^{\circ} \mathrm{C}$ rise in temperature associated with $1.5 \%, 2.5 \%, 2.2 \%$ and $-1.2 \%$ increases in mortality for all natural deaths, and deaths in levels 1, 2 and 3, respectively. This indicates that the cumulative effect on mortality up to 21 days is about the same as it is up to 4 days and that there is no evidence of short-term harvesting.

Table 2. Results of generalised additive models (GAM) with linear terms for all environmental parameters from May to October 1999-2008.

\begin{tabular}{|c|c|c|c|c|c|c|c|c|}
\hline & $\begin{array}{c}\text { Mean } \\
\text { temperature } \\
1{ }^{\circ} \mathrm{C} \text { rise } \\
\%(95 \% \mathrm{CI})\end{array}$ & P-value & $\begin{array}{l}\text { Relative } \\
\text { humidity } \\
10 \% \text { rise }\end{array}$ & P-value & $\begin{array}{l}\text { Wind speed } \\
1 \mathrm{~m} / \mathrm{s} \text { drop }\end{array}$ & P-value & $\begin{array}{l}\text { Ozone content } \\
10 \text { ppb rise }\end{array}$ & P-value \\
\hline All levels & $\begin{array}{c}1.4 \% \\
(0.3 \%, 2.5 \%)\end{array}$ & 0.014 & $\begin{array}{c}0.5 \% \\
(-2.1 \%, 3.2 \%)\end{array}$ & 0.961 & $\begin{array}{c}0.7 \% \\
(-1.2 \%, 2.7 \%)\end{array}$ & 0.478 & $\begin{array}{c}0.4 \% \\
(-0.9 \%, 1.7 \%)\end{array}$ & 0.577 \\
\hline \multicolumn{9}{|l|}{ District Class } \\
\hline Level 1 & $\begin{array}{c}2.8 \% \\
(-0.7 \%, 6.4 \%)\end{array}$ & 0.119 & $\begin{array}{c}7.6 \% \\
(-1.4 \%, 17.5 \%)\end{array}$ & 0.100 & $\begin{array}{c}-2.7 \% \\
(-8.4 \%, 3.4 \%)\end{array}$ & 0.377 & $\begin{array}{c}3.7 \% \\
(-0.5 \%, 8.1 \%)\end{array}$ & 0.082 \\
\hline Level 2 & $\begin{array}{c}2.3 \% \\
(0.8 \%, 3.8 \%)\end{array}$ & 0.002 & $\begin{array}{c}1.3 \% \\
(-2.2 \%, 5.0 \%)\end{array}$ & 0.463 & $\begin{array}{c}0.8 \% \\
(-1.8 \%, 3.5 \%)\end{array}$ & 0.546 & $\begin{array}{c}0.8 \% \\
(-0.9 \%, 2.6 \%)\end{array}$ & 0.359 \\
\hline Level 3 & $\begin{array}{c}-1.2 \% \\
(-3.4 \%, 1.1 \%)\end{array}$ & 0.300 & $\begin{array}{c}-2.5 \% \\
(-7.2 \%, 2.4 \%)\end{array}$ & 0.296 & $\begin{array}{c}2.8 \% \\
(-0.8 \%, 6.5 \%)\end{array}$ & 0.131 & $\begin{array}{c}-0.7 \% \\
(-3.1 \%, 1.6 \%)\end{array}$ & 0.553 \\
\hline Level $1+$ Level 2 & $\begin{array}{c}2.3 \% \\
(1.0 \%, 3.7 \%)\end{array}$ & 0.001 & $\begin{array}{c}1.8 \% \\
(-1.5 \%, 5.2 \%)\end{array}$ & 0.277 & $\begin{array}{c}0.1 \% \\
(-2.3 \%, 2.5 \%)\end{array}$ & 0.949 & $\begin{array}{c}1.2 \% \\
(-0.4 \%, 2.8 \%)\end{array}$ & 0.154 \\
\hline \multicolumn{9}{|l|}{ Age at death } \\
\hline$<65$ & $\begin{array}{c}-0.3 \% \\
(-1.2 \%, 1.7 \%)\end{array}$ & 0.762 & $\begin{array}{c}0.8 \% \\
(-3.8 \%, 5.7 \%)\end{array}$ & 0.737 & $\begin{array}{c}0.8 \\
(-2.7 \%, 4.5 \%)\end{array}$ & 0.660 & $\begin{array}{c}-0.8 \% \\
(-3.1 \%, 1.5 \%)\end{array}$ & 0.493 \\
\hline $65-74$ & $\begin{array}{c}1.8 \% \\
(-0.5 \%, 4.1 \%)\end{array}$ & 0.123 & $\begin{array}{c}0.7 \% \\
(-4.6 \%, 6.4 \%)\end{array}$ & 0.787 & $\begin{array}{c}0.4 \% \\
(-3.6 \%, 4.5 \%)\end{array}$ & 0.849 & $\begin{array}{c}0.5 \% \\
(-2.3 \%, 3.3 \%)\end{array}$ & 0.735 \\
\hline$\geq 75$ & $\begin{array}{c}2.3 \% \\
(0.7 \%, 4.0 \%)\end{array}$ & 0.005 & $\begin{array}{c}0.3 \% \\
(-3.5 \%, 4.4 \%)\end{array}$ & 0.862 & $\begin{array}{c}0.9 \% \\
(-2.0 \%, 3.9 \%)\end{array}$ & 0.545 & $\begin{array}{c}1.1 \% \\
(-0.8 \%, 3.1 \%)\end{array}$ & 0.240 \\
\hline
\end{tabular}


Table 3. Results of generalised additive models (GAM) with piecewise temperature terms.

\begin{tabular}{|c|c|c|c|c|}
\hline $\begin{array}{l}\text { District class/ } \\
\text { No. of deaths/ } \\
\text { Age }\end{array}$ & $\begin{array}{c}\text { Change of mean temperature } \\
\text { rise of } 1{ }^{\circ} \mathrm{C} \text { above } 29^{\circ} \mathrm{C} \\
\%(95 \% \mathrm{CI})\end{array}$ & P-value & $\begin{array}{c}\text { Change of mean temperature } \\
\text { rise of } 1{ }^{\circ} \mathrm{C} \text { below } 29^{\circ} \mathrm{C} \\
\%(95 \% \mathrm{CI})\end{array}$ & P-value \\
\hline Level 1 & $4.2(-5.2,14.5)$ & 0.360 & $2.3(-6.3,11.7)$ & 0.303 \\
\hline Level 2 & $5.0(1.2,8.9)$ & 0.010 & $1.4(-0.5,3.3)$ & 0.146 \\
\hline Level 3 & $0.3(-4.7,5.6)$ & 0.899 & $-1.6(-4.7,1.2)$ & 0.241 \\
\hline Levels $1+2$ & $4.6(1.2,8.2)$ & 0.009 & $1.5(-0.2,3.3)$ & 0.085 \\
\hline All natural deaths & $3.4(0.6,6.3)$ & 0.017 & $0.7(-0.7,2.1)$ & 0.342 \\
\hline Age $<65$ years & $3.9(-1.2 \%, 9.4)$ & 0.139 & $-1.7(-4.2,0.8)$ & 0.191 \\
\hline Age $65-74$ years & $3.0(-2.7 \%, 9.0)$ & 0.317 & $1.4(-1.4,4.3)$ & 0.344 \\
\hline Age $\geq 75$ years & $3.5(-0.5 \%, 7.6)$ & 0.093 & $1.9(-0.2,4.0)$ & 0.079 \\
\hline
\end{tabular}

\section{Discussion}

This, our second study in a tropical Asian city, shows that meteorological variables only substantially affect mortality in areas subject to UHI effects. The major finding is the statistically significant, shortterm increase in mortality during periods of higher temperatures in Kaohsiung, which did not appear to be due to "harvesting", and was significantly stronger in districts classified as requiring high (level 1) or medium (level 2) planning input according to the UCMap methodology. There was no significant effect of high temperatures in level 3 districts, i.e. those classified as only requiring preservation of existing conditions. The overall association between RH percent, mean wind speed and ozone levels and mortality were all non-significant, although higher $\mathrm{RH}$ and ozone were close to significant predictors of mortality in the "hot" areas.

In order to check if observed differences between classes of districts might be due to confounding by other characteristics of the districts we also examined the age distribution of the deaths in the districts and the average socioeconomic status (SES) of the districts population. The percentages of deaths occurring in subjects that were $<65$ years old, $65-74$ years old and 75 + years old were $23 \%, 25 \%$ and $52 \%$, respectively; in level 1 districts, $31 \%, 26 \%$ and $43 \%$ in level 2 districts, respectively; and $26 \%, 25 \%$ and $49 \%$ in level 3 districts, respectively. Thus, while the distribution of deaths in "hot" districts was slightly weighted to the older age groups than for level 3 districts, deaths in level 2 districts were the youngest and, overall, the deaths in the Level 3 areas were older than those in levels 1 and 2, which rules out confounding by age. While it is difficult to completely rule out confounding by SES as only district level SES indicators were available. Among the population 15 years of age or older residing in level 1 districts the percentage who had university degrees was $19.5 \%$ which is slightly higher than the percentages for those residing in level $2,16.3 \%$ and level $3,16.4 \%$. The percentage of residents in level 1 districts classified as 'low income' was $1.4 \%$, while the corresponding percentages for level 2 and level 3 districts were both $1.6 \%$. Given the small differences in SES between district classes we believe that confounding by SES is very unlikely.

Our findings regarding high temperature effects are similar to those of our previous study conducted with data from Hong Kong (Goggins et al., 2012). In that study we estimated an increase in mortality of $4.1 \%$ per $1{ }^{\circ} \mathrm{C}$ rise (lags $\left.0-4\right)$ above $29^{\circ} \mathrm{C}$ for areas with UHII above the median versus a $0.7 \%$ rise for UHII below the median. These findings are quite close to our findings for Kaohsiung, except that for Hong Kong we found a U-shaped mortality-temperature association during the hot season with an inverse association between higher temperature and mortality for temperatures below $28{ }^{\circ} \mathrm{C}$, albeit the association was slight and non-significant. For Kaohsiung, on the other hand, the association between temperature and mortality was positive throughout the range observed in the hot season. Although Hong Kong has a sub-tropical climate, the distribution of temperatures during its shorter hot season (June-September) is nearly identical to that observed for the longer hot season in tropical Kaohsiung. An important difference between our results for Kaohsiung and those for Hong Kong concerns the association between wind speed and mortality. Lower wind speed was found to be an important and significant predictor of higher mortality in Hong Kong hot areas but without effect in the cool areas, a finding explained by the exacerbation of UHI effects on days with little wind. In Kaohsiung, the overall effect of wind speed was 
slight and non-significant but it was stronger, although still non-significant, in the cool areas of the city (level 3). A possible reason for this difference is that the distribution of wind speeds is very different between the two cities. The mean wind speed in Kaohsiung $(2.2 \mathrm{~m} / \mathrm{s}$ or $7.9 \mathrm{~km} / \mathrm{h})$ is only about the $5^{\text {th }}$ percentile of the wind speed in Hong Kong, which has a mean speed of about $20.5 \mathrm{~km} / \mathrm{h}$. Thus, wind speed in Kaohsiung may normally be insufficient to have much mitigating effect. Also the variation in wind speed is much smaller in Kaohsiung $(\mathrm{SD}=2.7$ versus $10.6 \mathrm{~km} / \mathrm{h}$ for Hong Kong) making detection of an effect more difficult.

Other studies looking at intra-urban differences in heat effects have used various methods to classify areas of the city by potential differences in micro-climate. A study from Montreal (Smargiassi et al., 2009) used two satellite thermal images to classify areas as either hot or cool based on surface temperatures finding that the odds of mortality for a $26{ }^{\circ} \mathrm{C}$ day versus a $20{ }^{\circ} \mathrm{C}$ day were $28 \%$ higher in hot areas but only $13 \%$ higher in cool areas. A German study (Gabriel and Endlicher, 2011) used the proportion of each district covered by sealed surfaces as a proxy for UHI effects, finding a positive correlation between this proportion and district mortality rates during periods of stress due to high heat. Other studies have looked at differences between urban and suburban/rural areas in heat effects on mortality. A study from Shanghai (Tan et al., 2010) found that excess mortality during the 1998 heat wave was about four times as high in urban areas compared to areas outside the city, while a study from Bangladesh (Burkart et al., 2011) found a rise in mortality of $7.5 \%$ per $1{ }^{\circ} \mathrm{C}$ increase in temperature above $28.8^{\circ} \mathrm{C}$ in urban areas versus a considerably lower rise $(1.5 \%)$ in rural areas. An advantage of using the UCMap to do the classification is that this method takes into account several different environmental parameters when evaluating urban microclimates. Thus, for example, Kaohsiung's Cijin district, which is a long, narrow island, has a high population density and a high UHII, but was classified as level 3 by the UCMap due to its seafront location. Likewise, the Siaogang district, which has a low population density and low UHII was classified as level 2 due to a large amount of industrial activity and lack of greenery. In separate analyses, these classifications appear to be partially supported by our data as Siaogang showed a large temperature effect on mortality, particularly above $29^{\circ} \mathrm{C}$ (although non-significant due to the small sample size), while Cijin showed only a small inverse association.
Our finding of a significant association between extreme high temperatures and mortality is consistent with most other studies. Research specifically looking at heat effects in cities with tropical climates is not as common as research on heat effects in cities with temperate or sub-tropical climates. However, the ISOTHURM study (McMichael et al., 2008) included two cities with tropical climates: Bangkok in Thailand and Salvador in Brazil. Mortality in the former city was found to rise on average by $5.78 \%$ per $1{ }^{\circ} \mathrm{C}$ temperature rise (lags 0-1) above $29{ }^{\circ} \mathrm{C}$, while for Salvador a $2.48 \%$ rise in mortality was found for rises of $1{ }^{\circ} \mathrm{C}$ above a threshold of $23^{\circ} \mathrm{C}$. A multi-city study from the United States of America (Curriero et al., 2002) included one tropical city: Miami in the state of Florida, which showed a $4.01 \%$ rise in mortality per 1 ${ }^{\circ} \mathrm{C}$ rise in same-day temperature above the minimum mortality temperature of $27.2^{\circ} \mathrm{C}$.

The major strengths of our study are (i) the inclusion of the use of a comprehensive classification method for urban climatic conditions (UCMap), (ii) the availability of long time-series of data (10 years), and (iii) the use of sophisticated statistical methodology, which controlled for possible confounders and accounted for lagged effects.

A limitation, which is shared by other studies of this nature, is the fact that our meteorological and pollutant variables were measured outdoors at fixed monitoring stations and thus may not represent the conditions to which individuals are actually exposed. Another limitation is that mortality counts were only available at the district level. Since urban climatic conditions varied within districts as well, some decedents in level 1 or level 2 districts may have actually lived in areas of these level 3 districts and vice versa.

\section{Conclusion}

There is a significant positive association between high temperature and mortality during the hot season in Kaohsiung, but only in areas of the city judged to have urban climatic and environmental characteristics which exacerbate the UHI effects. However, the sharp rate of increase in mortality for temperatures over $29^{\circ} \mathrm{C}$ suggests that climate change could have a more adverse impact on mortality in the future.

Urban planning designed to lessen the effects of UHI is an important adaptation measure in the face of inevitable rising temperatures in the near future, which does not only have the potential to provide more comfortable living conditions for urban populations, but would indeed improve health. 


\section{References}

Armstrong B, 2006. Models for the relationship between ambient temperature and daily mortality. Epidemiology 17, 624-631.

Braga ALF, Zanobetti A, Schwartz J, 2002. The effect of weather on respiratory and cardiovascular deaths in 12 U.S. cities. Environ Health Perspect 110, 859-863.

Burkart K, Schneider A, Breitner S, Khan MH, Kramer A, Endlicher W, 2011. The effect of atmospheric thermal conditions and urban thermal pollution on all-cause and cardiovascular mortality in Bangladesh. Environ Pollut 159, 2035-2043.

Carder M, McNamee R, Beverland I, Elton R, Cohen GR, Boyd J, Agyus RM, 2005. The lagged effect of cold temperature and wind chill on cardiorespiratory mortality in Scotland. Occup Environ Med 62, 702-710.

Chan EYY, Goggins WB, Kim JJ, Griffiths SM, 2012. A study of intracity variation of temperature-related mortality and socioeconomic status among the Chinese population of Hong Kong. J Epidemiol Community Health 66, 322-327.

Curriero FC, Heiner KS, Samet JM, Zeger SL, Strug L, Patz JA, 2002. Temperature and mortality in 11 cities of the eastern United States. Am J Epidemiol 155, 80-87.

Gabriel KMA, Endlicher WR, 2011. Urban and rural mortality rates during heat waves in Berlin and Brandenburg, Germany. Environ Pollut 159, 2044-2050.

Goggins WB, Chan EYY, Ng E, Ren C, Liang C, 2012. Effect modification of the association between short-term meteorological factors and mortality by urban heat islands in Hong Kong. PLoS One 7, e38551.

Hosking J, Campbell-Lendrum D, 2012. How well does climate change and human health research match the demands of policymakers? A scoping review. Environ Health Perspect 120, 1076-1082.

Ishigami A, Hajat S, Sari Kovats R, Bisanti L, Rognoni M, Russo A, Paldy A, 2008. An ecological time-series study of heat-related mortality in three European cities. Environ Health 7,5 .

Kaohsiung City Government, 2011. The Statistical Yearbook of Kaohsiung City 2010. Department of Budget, Accounting and Statistics, Republic of China. Available at: http://dbaskmg.kcg.gov.tw/english/statistics/download/yearbook.pdf (accessed on August 2012).

Luber G, McGeehin M, 2008. Climate change and extreme heat events. Am J Prev Med 35, 429-435.

McMichael AJ, Wilkinson P, Kovats RS, Pattenden S, Hajat S, Armstrong B, Vajanapoom N, Niciu EM, Mahomed H, Kingkeow C, Kosnik M, O’Neill MS, Romieu I, RamerizAguilar M, Barreto ML, Gouveia N, Nikiforov B, 2008. International study of temperature, heat and urban mortality, the 'ISOTHURM' project. Int J Epidemiol 37, 1121-1131.

Pielke R, Prins G, Rayner S, Sarewitz D, 2007. Lifting the taboo on adaptation. Nature 445, 597-598.

Ren C, Lau KL, Yiu KP, Ng E, 2013. Application of urban climatic mapping into the urban planning of high density cities: the case of Kaohsiung, Taiwan. Cities 31, 1-16.

Ren C, Ng E, Katzschner L, 2011. Urban climatic map studies: a review. Int J Climatol 31, 2213-2233.

Smargiassi A, Goldberg MS, Plante C, Fournier M, Baudouin Y, Kosatsky T, 2009. Variation of daily warm season mortality as a function of micro-urban heat islands. J Epidemiol Community Health 63, 659-664.

Tan J, Zheng Y, Tang X, Guo C, Li L, Song G, Zhen X, Yuan D, Kalkstien AJ, Li F, 2010. The urban heat island and its impact on heat waves and human health in Shanghai. Int J Biometeorol 54, 75-84.

Tsai SS, Chiu HF, Wu TN, Yang CY, 2009. Air pollution and emergency room visits for cardiac arrhythmia in a subtropical city: Taipei, Taiwan. Inhal Toxicol 21, 1113-1118.

Wood S, 2006, Generalised additive models an introduction with R. Chapman and Hall/CRC; Taylor and Francis Group. 